\title{
La apropiación del nouchi por el francés marfileño en el lenguaje juvenil: un fenómeno de variación sociolingüística
}

\author{
The appropriation of "nouchi" by the Ivorian French in youth \\ language: a phenomenon of sociolinguistic variation
}

YaO Koffl

Departamento de Estudios Ibéricos y Latinoamericanos

Universidad Félix Houphouët-Boigny, Costa de Marfil

\section{Resumen}

La apropiación del "nouchi" por el francés marfileño es un fenómeno de adopción o transferencia de ciertas neologías expresivas y otros préstamos particulares al lenguaje juvenil. En relación con este proceso, nuestro estudio plantea la problemática de la emergencia del francés local apoyándose en estos elementos léxicos metódicamente seleccionados mediante la escucha de materiales musicales, zouglou, coupé-décalé y rap, con el fin de comprobar tanto la influencia de estos géneros musicales, como los procesos de (trans) formación de esta variedad particular de la lengua francesa.

Palabras clave: apropiación, neología, lenguaje juvenil, nouchi, francés marfileño

\section{Abstract}

The appropriation of the "nouchi" by the Ivorian French is a phenomenon of adoption or the transfer of some expressive neologies and other particular loan words to the juvenile language. In relation to this process, our study raises the problem of the emergence of local French based on these lexical elements methodically selected by listening to musical materials,"zouglou", "coupé-décalé" and rap, in order to check both the influence of these musical genres, and the processes of (trans)formation of this particular variety of the French language.

Keywords: appropriation, neologies, juvenile speaking, nouchi, ivorian french 


\section{Introducción}

$\mathrm{E}$ n la actualidad, la Organización Internacional de la Francofonía (OIF) atribuye el 54,7\% de francófonos al continente africano. Este dato revela la vitalidad de la lengua francesa cuya expansión comienza con la política de imposición y/o de asimilación lingüística iniciada desde la colonización, en el siglo XIX, y desemboca, a juicios de Kouadio (2003), en la "apropiación sin complejos" de la lengua del colonizador por parte de varios países africanos, como Costa de Marfil.

Cabe señalar que este proceso atinente a la variación policéntrica del francés, supone la adaptación de varios fenómenos lingüísticos, junto con factores culturales, sociolingüísticos y geolectales. En este mismo sentido, el francés hablado en Costa de Marfil ha experimentado profundos cambios estructurales que evidencian la autonomización de esta variedad denominada: "le français ivoirien" (francés marfileño). Ahua Martial (2018) lo describe como un sistema basado en la reproducción estructural y sintáctica de lenguas nativas. Lo que viene a ser una traducción literal de palabras y expresiones de lenguas marfileñas, junto con el uso de abundantes préstamos.

Dicho proceso implica también la formación de numerosas unidades neológicas particulares que proceden de diferentes fuentes como, en este caso, los géneros musicales locales: "zouglou", "coupé-décalé" y rap marfileño. Partiendo de esta observación, cobra fuerza la hipótesis según la cual no solo estos géneros contribuyen al enriquecimiento del francés marfileño, sino que también fomentan su desarrollo y autonomización en tanto sistema particular. Asimismo, se intenta dar cuenta de los medios y fenómenos que intervienen en la formación de esta variedad policéntrica del francés, apoyándose en aquellos elementos léxicos y expresivos característicos y difundidos mediante los géneros musicales señalados. Siguiendo este planteamiento, el presente estudio se desarrollará en torno a tres grandes ejes. De entrada, se presentará el tema y los objetivos que se le asignan. Luego, se procederá a la exposición de los conceptos relevantes, seguidos del análisis léxico-semántico de los componentes del corpus y, por último, se tratarán los resultados mediante el análisis pormenorizado de los datos registrados, antes de elaborar la conclusión general.

Presentación del tema. Este estudio centrado en la investigación lexicológica, trata de explicar el fenómeno de apropiación del argot nouchi por el francés marfileño, basándose en algunos préstamos y expresiones neológicas de los géneros musicales: el "zouglou", el "coupé-décalé" y el rap, que suelen emplearse en el habla de los jóvenes.

De hecho, como locutores y conocedores del estilo comunicativo de los nativos, algunos artistas se dedican a divulgar términos y expresiones neológicas en nouchi, mediante una retórica particular, tendente a cautivar a melómanos y hablantes jóvenes. Asimismo, al comprobar la entrada y el arraigo de estas formas verbales: "wolosso", "choco", "chien mange pas chien", "enfant de boss c'est boss", etc., en el francés local, resultó tan necesario como pertinente dedicar este estudio analítico y descriptivo a este fenómeno sociolingüístico singular. 
Si bien nuestro interés principal es dar a conocer los fenómenos que influyen en la variación policéntrica del francés marfileño, como consecuencia de la convergencia y adaptación de fenómenos lingüísticos, los objetivos que se asignan a esta exploración son diversos: 1. Mostrar cómo se opera la apropiación del nouchi por el francés marfileño a través de neologismos léxicos y expresivos que se introducen mediante algunos géneros musicales; 2. Entender la relación entre la música como medio de comunicación y el francés marfileño; 3. Valorar el impacto de la música sobre el aprendizaje de lenguas; y 4. Dar a conocer los cambios actuales que afectan el paradigma léxicosemántico y sociolingüístico.

A pesar de ser una iniciativa novedosa, este estudio centrado en las aportaciones verbales procedentes de los géneros musicales señalados no podría emprenderse sin referirse a quienes iniciaron la investigación sobre la emergencia del francés marfileño. Asimismo, habría que citar a Duponchel (1972, 1975), uno de los referentes en la investigación lexicológica sobre el francés hablado en este país. En la línea investigadora de este africanista, se sitúa la ingente obra de Kouadio y Tymian (1979, 2007), junto con lingüistas como Ngalasso y Ploog (1998), además de Lafage (2002), que tratan de explicar los mismos procesos lexicogenéticos, poniendo de manifiesto la ingeniosidad y creatividad de los hablantes.

A la vista de los datos cuantitativos y cualitativos registrados, Aboa (2008), al igual Yao $(2011,2013)$ y otros, se suma a esta labor científica para dar cuenta de la evolución del francés marfileño.

\section{Marco teórico}

En relación con los requerimientos teóricos, se analizarán los conceptos fundamentales que permiten entender la preocupación expuesta. Se tratará de explicar dichos conceptos, sumando a ello la contribución de otros estudiosos que se ocuparon de entender la formación del francés marfileño o su enriquecimiento mediante la aportación de géneros musicales.

Definición de conceptos fundamentales. Este tema se asienta en conceptos que requieren una aclaración definicional para dar coherencia a su análisis. En esta perspectiva, entendemos que la música y el lenguaje son dos fenómenos o prácticas sociales que guardan ciertas similitudes, por lo que sería necesario explicarlos en paralelo.

\section{El principio de la apropiación lingüís-} tica mediante la música. La apropiación lingüística y la música como lenguaje son los dos temas que ocupan nuestra atención. Asimismo, cabe señalar que la transferencia de elementos estructurales de un subsistema o lengua de especialidad a la lengua de una comunidad se considera un fenómeno de apropiación lingüística. Como proceso idiosincrático o sociolectal, se ve favorecido, en este caso, por la relación asimétrica entre el nouchi (argot) y el francés marfileño, como lengua dominante. Mientras que la música, como expresión artística y cultural, se considera lenguaje simbólico universal. Esta concepción cobra mayor fuerza teniendo en cuenta la música como arte asociada con la palabra para materializar el sentir colectivo. Asimismo, Llamas (2011) admite que música y 
lengua son realidades complementarias, dado que algunos aspectos del lenguaje verbal resultan musicales y otros de la música son lingüísticos.

Además, como práctica cultural, conlleva una enorme influencia afectiva que lo convierte en un poderoso instrumento de movilización social y de concienciación identitaria. En este sentido, Cross (2010, p. 11) señala "su rol significativo en los procesos de formación intelectual, histórico y comunicativo”. A juicio de Platón, constituye un factor de cohesión social, aunque también se puede convertir en un factor de desagregación social. En suma, la música representa una manifestación esencial de los valores culturales, así como de los sentimientos de pertenencia a la comunidad. Tras estas aproximaciones definicionales, presentamos a continuación los géneros musicales.

El zouglou. El zouglou es conocido como género musical popular y urbano de Costa de Marfil. Se particulariza por su ritmo basado en la música tradicional de la etnia bété y su alto compromiso con la realidad. Asimismo, se focaliza sobre todo en la vivencia de la juventud marfileña, en la política, etc., haciendo críticas en tono humorístico, sobre cualquier tema o problema del momento.

Tiene su origen en el llamado "woyo o woyor", nombre que se da a pequeños grupos de cantantes que actúan, sirviéndose de instrumentos tradicionales, maracas, djembé (tambor marfileño), en la celebración de bodas, funerales, etc. Ellos producen lo que se conoce como "ambiance facile", es decir, una animación espontánea.

Este género musical se introdujo en torno a los años 1990, en el campus universitario de Abiyán, capital económica de Costa de Marfil, con una instrumentación musical moderna. Se denominó zouglou, para expresar la amargura del pueblo marfileño sumido en una profunda crisis económica, social y política. Así, con su música reivindicativa, aquellos estudiantes aparecieron como el portavoz de ese pueblo amordazado por el régimen monopartidista y totalitario del padre de la independencia, el presidente Félix Houpouët-Boigny.

Desde entonces, el interés que fue generando este fenómeno musical en la población suscitó la formación de diversos grupos, entre los cuales podríamos nombrar a los más destacados e influyentes: Poussins chocs, Les Garagistes, Systèmes gazeur y Parents du campus, bajo el liderazgo de Didier Bilé, uno de los pioneros de este movimiento. En su evolución, el zouglou dio otros subgéneros como Gnapka gnapka, Pkaklo, etc., desarrollados por nuevos seguidores como: Petit Denis, Espoir 2000, Les garagistes, Les patrons, Vieux gazeur, Les galiers, Yode et Siro, etc.

El coupé-décalé. El coupé-decalé apareció en el 2002, en los albores de la guerra civil de Costa de Marfil. Surgió cuando la diáspora marfileña de Francia se planteó apoyar a su país con bailes y músicas alegres, aliviando a la población afligida por las contiendas. En concreto, este movimiento o fenómeno sociológico surgió por iniciativa de un joven marfileño Douk Saga, conocido como el rey de la Jet-Set. Fue inicialmente una moda urbana o, más bien, un estilo de baile cuyos pioneros se denominaban los boucantier ${ }^{1}$. Al arraigarse, se convirtió en un género musical. Así, además de su baile y música particular, se desmarcaban por 
su vestimenta ostentosa, una forma de alardear exhibiendo una apariencia alegre para reflejar una vida placentera y lujosa. De allí viene el apodo: la Jet-Set, nombre que se da al colectivo de boucantier.

El movimiento tuvo tal impacto que fue acogido por toda la sociedad marfileña deseosa de cambiar de página y disfrutar de la vida, pasando del incesante conflicto en el que los políticos habían hundido su país. Tuvo numerosísimos adeptos entre la juventud y varios seguidores que lo llevaron más allá de las fronteras nacionales. Hoy en día el coupé-décalé se ha convertido en un movimiento artístico y cultural inconfundible mediante el cual se identifica el pueblo marfileño.

El rap. Hizo su entrada en Costa de Marfil en 1985, de la mano del artista y presentador Zogbo Junior, al volver a su país, tras una larga estancia en Francia. Es preciso referirse a este género musical como rap marfileño, porque, aun siendo de origen hip-hop, ha ido desligándose de este último para convertirse en una música popular nativa. En 1990, ya se había afianzado $y$, desde entonces, al popularizarse, se ha convertido en seña de identidad cultural de Costa de Marfil. Se registran cada vez más grupos musicales $\mathrm{y}$, entre ellos, habría que mencionar a los más influyentes como Ras, Les gis, Crazy boys, Almighty, etc. En general, se hicieron un hueco en el escenario musical nacional gracias a su letra y las expresiones neológicas particulares en lenguaje nouchi, con estas asumen un enorme compromiso con la realidad social.

\section{Marco metodológico y recursos analíticos}

El estudio resulta de la confluencia de diferentes métodos que fueron necesarios tanto para la recogida de datos como para el análisis estructural de los elementos.

Recopilación de datos. Se fundamenta en la recogida selectiva de palabras y expresiones, mediante la escucha de diversos títulos de álbumes musicales realizados desde 1985, año cuando iniciaron estos fenómenos musicales.

Asimismo, se llevó a cabo un estudio de campo mediante una encuesta directa a unos 30 informantes ${ }^{2}$ para evidenciar los datos. Esta labor sirvió tanto para valorar la influencia que pudieron ejercer los elementos verbales recogidos sobre los propios locutores, como para medir su grado de arraigo. Para dar cuenta de dicho impacto, el estudio se basó en varios factores sociológicos: la edad, el nivel de estudio, la profesión y el interés por los géneros musicales señalados.

Análisis de datos. Los datos fueron sometidos a una descripción morfosintáctica y léxico-semántica. Este análisis que explica la estructura formal de unidades neológicas, junto con su semantismo particular, resultó tan interesante como necesario para conocer el proceso de formación del francés marfileño. A este efecto, proporcionamos un corpus de 46 neologismos y expresiones fraseológicas del zouglou, el coupé-décalé y el rap que representan, a nuestro entender, los géneros musicales más influyentes tanto en la sociedad como en el francés marfileño. 


\section{Situación sociolingüística de Costa de Marfil}

Costa de Marfil es un país multilingüe y multicultural. Consta aproximativamente de unas 60 lenguas nativas que se clasifican entre 4 grandes grupos: los akan, los malinké, los gur y los krou. Bajo el imperio colonial francés, estas lenguas entraron en contacto con el francés, por lo que se inicia una cohabitación lingüística. Al francés, se añaden otras lenguas europeas, introducidas en este país como consecuencias de los intercambios impuestos por el imperialismo lingüístico y cultural inherente al fenómeno de globalización. Así, tendremos junto al francés, el inglés, el español, el alemán y el portugués que se está estableciendo paulatinamente durante los últimos años.

El francés estándar frente al francés de Costa de Marfil. El francés se impuso como lengua oficial desde el periodo colonial y es el único medio de comunicación de las instituciones públicas (la enseñanza, los medios audiovisuales, la prensa, la administración, etc.). Sin embargo, a pesar de gozar de este estatus privilegiado, no ha logrado sobreponerse sistemáticamente a las lenguas nativas (infravaloradas y relegadas al plano informal). La cohabitación de ambos sistemas engendró, no solo la (con) fusión de fenómenos estructurales, sino que también ha creado varias clases de hablantes que difieren según las competencias lingüísticas. Unos son bilingües completos (intelectuales) y otros, bilingües parciales (mayoritariamente analfabetos: obreros, campesinos, etc.). La conjunción de estos factores competenciales y sociolingüísticos acarrea el nacimiento del francés marfileño.
Tipología del francés marfileño frente al francés estándar. Según Kouadio y Koia (2007), el francés marfileño se caracteriza formalmente por diversos préstamos y neologismos, y su sintaxis particular se asienta en la estructura tipológica de las lenguas nativas. Como variedad policéntrica o regional, es también llamado francés local y constituye la variedad más usual, una lengua franca mediante la cual los nativos se comunican a diario. Además, como ya señalamos, esta variedad es tributaria de la morfosintaxis y de los modos de enunciación y de conceptualización en las lenguas marfileñas.

Así, conlleva varios fenómenos lingüísticos copiados del sustrato local. Por un lado, suelen registrarse la dilatación vocálica (“J'ai travaillé jusqu' en en j'ai dix ans"); y los empleos onomatopéyicos ("J'ai tapé kokokokoko, ils n'ont pas entendu"). También, hace frecuentemente uso de partículas dictomodales ("poulet est doux deh!", por "bon poulet" -iMuy bueno el pollo!--). Estos ejemplos ilustran el funcionamiento léxico-semántico particular del francés marfileño, que usa además abundantes reduplicaciones de palabras, a modo de énfasis. A estos procedimientos léxico-semánticos, se añaden calcos fraseológicos basados en expresiones locales; por ejemplo: "Attraper le coeur", por "être courageux" (ser valiente); "Gâter la tête" por "manipuler" (manipular), etc.

\section{El francés marfileño y sus variantes}

Debe distinguirse de lo que se podría considerar el francés estándar local. El francés popular marfileño es la variedad inicial derivada de la coexistencia entre 
el francés y las lenguas nativas. Puede decirse que es un pidgin utilizado para comunicarse con los auxiliares africanos. Se trata de una lengua mixta que asume algunas funciones de comunicación cotidiana. Este francés popular se caracteriza por:

Nivel morfosintáctico: caracterizado por la desaparición de la categoría del género y del número, el no-respeto de la flexión verbal con la generalización de todos los verbos de la forma del participio pasado, la ausencia de conjunciones, preposiciones, determinantes y una restructuración a partir del modelo de las lenguas marfileñas.

Nivel fonético: caracterizado por una pronunciación aproximativa, la confusión de fonemas y el desconocimiento de las fronteras de las palabras.

Nivel léxico-semántico: caracterizado por una yuxtaposición de los lexemas sin marcas gramaticales y el uso abundante de palabras polisémicas y de préstamos de las lenguas marfileñas.

Siguiendo las propiedades estructurales y sociolingüísticas descritas en las líneas anteriores, el francés marfileño posee diferentes registros o variantes que se emplean según la situación o el contexto comunicacional. Según Kouadio (2007), se distinguen tres registros fundamentales en el habla de los marfileños.

El francés acrolectal. Se puede identificar como francés estándar de nivel académico. También es el francés empleado por la elite intelectual. Según Bouttin (2002, p. 280), "L'acrolecte se présente comme le français soutenu et hypernormé avec des caractéristiques archaïsantes ou littéraires" .
El francés mesolectal. La variedad mesolectal del francés de Costa de Marfil corresponde a la población que tiene una educación secundaria. La sintaxis de este francés difiere muy poco de la del francés estándar, pero se caracteriza por resemantizaciones, préstamos léxicos y, muy a menudo, por expresiones particulares resultantes de la traducción literal de lenguas nativas. Por ejemplo, se empleará "gâter nom de quelqu'un" por "souiller le nom de quelqu'un" (ensuciar la imagen de alguien), tales expresiones son comunes en las producciones escritas y orales de la gran mayoría de los marfileños.

El francés basilectal. El origen de esta variedad del francés se remonta a 1934, cuando Abiyán se convierte en capital económica y política de Costa de Marfil. Las oportunidades de esta ciudad en desarrollo atraen a poblaciones de países vecinos (Malí, Burkina faso, Ghana, Guinea) y una avalancha de inversores extranjeros especialmente libaneses y sirios. Cabe señalar que el $75 \%$ de extranjeros que llegaba en aquella época era analfabeto. En general, esta población representaba una importante mano de obra, que trabajaba como subordinada para intelectuales o escolarizados que hablaban el francés con fluidez. Así, en relación con sus ocupaciones profesionales, los recién llegados se enfrentaron al problema de comunicación, lo cual les obligaba a una especie de argot o pidgin variopinto, mezcla de lenguas nativas y francés, sin normas gramaticales, correspondiente a la variante que denominamos el francés basilectal.

Este medio se transforma progresivamente $\mathrm{y}$, durante los últimos decenios del siglo XX, alcanza la unificación 
o la homogeneización de todas las variedades, alta (acrolecto), media (mesolecto) y baja (basilecto), formándose el francés marfileño.

El francés marfileño y el nouchi. El nouchi es uno de los componentes más importantes del paisaje sociolingüístico marfileño. Se trata de un argot que se desarrolló a partir de 1980, entre pandillas de jóvenes desescolarizados y/o marginados. Como tal, cumplía la función de un lenguaje críptico o especializado. Sin embargo, hoy en día, se ha desarrollado y está muy extendido, ya que la mayoría de los marfileños lo entienden y/o lo usan. Además, con el fenómeno de apropiación de este medio por parte del francés local, en los últimos decenios, se difuminan los límites estructurales entre ambos sistemas. Este proceso replantea la configuración sociolingüística de este país.

\section{Neologismos procedentes del zou- glou, coupé decalé y rap, y análisis de resultados}

Clases de unidades léxicas derivadas de los géneros musicales. La formación de neologismos. Un neologismo puede definirse como una palabra nueva que aparece en una lengua, o la inclusión de un significado nuevo en una palabra procedente de otra. La creación de neologismos se produce por modas y necesidades de nuevas designaciones, al margen de los neologismos innecesarios. Hoy en día, los medios de comunicación, al igual que la música, son los principales propagadores de los neologismos y de los préstamos lingüísticos. Como se evidenciará en el glosario proporcionado, entre los recursos lexicogenéticos, el préstamo léxico aparece como el procedimiento más productivo, a modo de ejemplo de esto, podemos mencionar palabras como: "bobraba", "douahou", "doubehi”, etc.

\section{Expresiones idiomáticas del francés} marfileño. Las expresiones idiomáticas son colocaciones verbales fijamente establecidas en el lenguaje que utilizamos conscientemente o inconscientemente cuando nos comunicamos. Al considerar los malentendidos que suelen producirse en la comprensión, se extiende la complejidad de dichos elementos en el proceso de comunicación. La dificultad de interpretación es muy recurrente en el uso de la expresión idiomática cuya traducción a otra lengua puede cambiar de significado cuando la lengua terminal no posee expresión equivalente. En lo que concierne al francés marfileño, se considera una variedad de lengua francesa hablada en Costa de Marfil. Se considera como una interlingua del resultado del contacto entre el francés estándar y las demás lenguas, ya que sean locales o extranjeras (inglés, español, etc.). Uno de los componentes esenciales de esta habla es el conjunto de expresiones idiomáticas. Veamos los siguientes ejemplos: a) Enlever camarade: esta expresión significa romper la amistad. Suele emplearse en el lenguaje juvenil para referirse al hecho de dejar de hablarse. Nótese que al introducirse en el francés local, cada componente de esta expresión experimenta una ampliación semántica en término de resemantización, ya que el verbo "enlever" (fr.), que significa quitar o retirar, pasa a significar romper, en esta colocación. Además, la palabra "camarade", cobra un semantismo muy amplio. 
Puede referirse a amigos, hermanos, etc. En francés metropolitano, corresponde a: "Ne plus se parler o ne plus être des amis". b) Etre bleu-bleu: significa, no enterarse de nada, por ejemplo: "Je suis bleu-bleu dans cette histoirelà ; que quelqu'un me l'explique". Se trata de un calco procedente de lenguas locales, pero, en su caso, se inspira del color "negro" en vez del "bleu" (azul). La particularidad de esta expresión se encuentra en la forma reduplicada del sustantivo/adjetivo bleu, que posee valor enfático o de intensificación, al contrario de la forma del francés "être bleu", que también significa: no enterarse de nada. El cambio de referencia cromática se explica en casi todas las lenguas locales puesto que, por su origen genético (familia Níger-congolesa), en su mayoría, poseen tan solo tres términos referentes al color (blanco, rojo, negro). Nótese que esta gama de tres colores representa un continuum cromático, en el que el azul se clasifica en el orden "negro". c) sauter dans sac: significa, agobiarse o molestarse inútilmente. El sentido literal equivaldría a: saltar en una bolsa, por ejemplo: "Si c'est à cause de cet argent que tu fais tout ce bruit, alors tu sautes dans sac car je ne te le donnerai pas". Se trata de una metáfora construida en alusión a un animal atrapado en una bolsa y que intenta inútilmente librarse o escaparse.

\section{Análisis morfológico y léxico-semántico de elementos léxicos del zouglou}

Neologismos y unidades fraseológicas del zouglou. Presentaremos en el orden sucesivo los elementos neológicos de cada género musical y las expresiones idiomáticas derivadas. Asimismo, empezaremos con el zouglou que representa, desde nuestro punto de vista, la primera fuente de abastecimiento del francés marfileño.

Neologismos del zouglou. BARA significa trabajo o tarea. Es un préstamo del dioula (lengua nativa del grupo malinké de Costa de Marfil), que -al introducirse en el francés marfileñoexperimenta una especialización semántica para referirse a las fechorías del llamado "brouteurs"3 (estafador especializado en la cibercriminalidad); por ejemplo: "Hier mon bara à payer ; ma vielle blanche a décaisser mon argent" (Ayer mi trabajo resultó; mi vieja blanca me mandó dinero). Esta palabra aparece en el álbum del artista Serge Benaud del 2016.

CALER significa no moverse ni un ápice (para zanjar un asunto en el acto). Se trata de un caso de ampliación semántica, ya que esta palabra posee también el significado original (fr. est.): mantener(se) firme. Al pasar al francés marfileño, esta palabra adquiere nuevos elementos sémicos y se aplica a la postura de una persona decidida a zanjar un asunto en el acto o sin moverse; por ejemplo: "Je suis calé devant ta porte on monte on descend mon argent va sortir" (Seguiré plantado delante de tu puerta, sea lo que sea, para que me devuelvas el dinero). Este ejemplo procede de la canción de 2016: "Je bois plus", del grupo Révolution.

DAHICO significa borracho. Se emplea como un sustantivo o un adjetivo; por ejemplo: "Tu ne vas jamais changer, tu es toujours dans ton dahico là" (No cambiarás nunca, no puedes dejar de ser un borracho), o "Je suis dahico" (Estoy borracho). Esta palabra se encuentra también en el álbum del grupo musical Revolution. 
DOUBEHI significa: querido(a). Se trata de un préstamo del bété ${ }^{4}$ al francés marfileño Resulta de la fusión de dos sustantivos: "dou" (pueblo) y "behi" (amigo). Corresponde literalmente a amigo del pueblo; por ejemplo: "Mon doubehi est le plus beau" (Mi querido es el más guapo). Aparece en el álbum Cessa kié la vérité, de 2005, del grupo Magic Système.

FLASHER significa estar confundido o no tener ni idea; literalmente, estar deslumbrado. Se trata de un neologismo verbal formado por derivación, amalgamando los componentes "flash" (destello o luz) del inglés y el morfema -er, del francés; por ejemplo: "Le devoir était si difficile que tous les élèves ont flashés" (El ejercicio era tan difícil que todos los alumnos se confundieron).

MOULER significa bailar. Se trata de una resemantización del verbo "mouler" (fr.), que se convierte en una palabra polisémica: amoldar (fr. est.) o bailar (fr. marf.). Se emplea con el sentido figurado y experimenta la ampliación semántica; por ejemplo: "Le weekend passé nous avons moulé jusqu'au petit matin" (El fin de semana pasado bailamos hasta la madrugada). Esta palabra aparece también en ya mencionado álbum del grupo Révolution.

TRACER significa largarse, irse escopetado. Se trata de un caso de resemantización del verbo "Tracer" (fr), que significa trazar. Sin embargo, al pasar al francés local, se emplea con el sentido figurado y experimenta a la vez una ampliación semántica. Ejemplo: "Je t’attends là [...] si tu ne viens pas dans les minutes qui suivent je vais tracer hein" (Te estoy esperando, si no vienes en los minutos siguientes, me largaré). Esta palabra aparece también en el señalado álbum del grupo musical Révolution.
Expresiones neológicas del zouglou. COUPER PAN significa aprovecharse económicamente de una persona y escabullirse. Procede de la combinación de dos elementos heterogéneos: "Couper" (fr.) que significa literalmente cortar. Al emplearse con sentido figurado en el francés marfileño, significa: arrebatarle algo a alguien. Se añade a este verbo el elemento "pan" del dioula, para referirse al hecho de abusar económicamente de alguien; por ejemplo: "Mon frère elle ta vi puis elle t'a coupé pan" (Hermano, ella te hizo soñar y abusó económicamente de ti).

FAIRE UN MOUGOU PAN significa escabullirse o escaquearse tras mantener relaciones sexuales con una persona. Se puede emplear como sustantivo; por ejemplo: "Ma chérie yako tu as été victime d'un mougou pan" (Amiga, fuiste víctima de un abuso sexual). También se emplea como expresión idiomática: "Faire un mougan pan"; por ejemplo: "Jean voulait faire un mougou pan mais, ayant vite perçu cette intention, Marie l'a éconduit". Se trata de una expresión idiomática también derivada del dioula. Se compone de la palabra "mougou" que significa literalmente moler y "pan" que significa salta o volar. Es una expresión figurada que se emplea como sinónimo de abusar sexualmente de una persona. Nótese que esta expresión fue acuñada por el artista Lunic, quien la publicó en su álbum Abidjan est risqué, realizado en el 2017.

TOMBER FAN significa enamorarse o sentir un flechazo. También, es una expresión amalgamada formada por la composición de las unidades léxicas: "tomber" (fr.) y el neologismo "fan" (derivado del inglés "fun"); por ejemplo: "Regarde-moi lui là il est 
tombé fan de la petite go là" (Mira a este, se ha enamorado de esta chiquita). Lunic lo emplea también en el álbum Abidjan est risqué.

ETRE POPODIPO significa estar plantado. Se suele usar para una persona decidida a zanjar un asunto en el acto; por ejemplo: "Je ne bouge pas aujourd'hui là je suis popodipo" (Hoy no me muevo. Hoy, me quedaré aquí plantado). Se emplea como sinónimo de "caler" que significa no moverse o mantenerse firme. Esta palabra aparece en "Un gaou à Paris", de 2003, del grupo Magic Système.

ETRE UN TAPÉ DOS significa putero o persona que pone cuernos. Se alude a la gente que aprovecha la ausencia del marido para ponerle los cuernos. En el sentido literal, significa golpear en la espalda. Suele emplearse también como sinónimo de adultero(a); por ejemplo: "Ne laisse pas ce Monsieur s'approcher de ta femme, car c'est un tapé dos" (No dejes que este hombre se acerque a tu mujer porque te pondrá los cuernos). Esta expresión está extraída del álbum $K i$ di mié del grupo Magic Système.

IL VA TE VADI significa golpear. Es una palabra que suele ser utilizada por los jóvenes. Es también una palabra polisémica, pues significa golpear o tener relaciones sexuales; por ejemplo: "Lui la tu le vois assis comme sa avec la fille là dans sa tête il va la vadi" (Lo ves sentado con esta chica; en su mente, quiere tener sexo con ella". Se encuentra esta expresión en el álbum Abidjan est risqué del artista Lunic.

PRENDRE POSITION significa disponerse, ponerse, prepararse (para embestir o atacar), ponerse en posición de ataque. Expresión neológica del nouchi. Significa literalmente, disponerse o colocarse para atacar; por ejemplo: "Façon il a pris position là c'est pour te tuer aujourd'hui" (Tal como se ha puesto, te va a matar hoy).

Aparece en el álbum Je bois plus, del grupo Révolution.

Neologismos y unidades fraseológicas del coupé-decalé. Neologismos del coupédécalé. BOBARABA significa nalgas gruesas o voluminosas. Es un préstamo del dioula al francés marfileño; por ejemplo: "C'est une vrai femme africaine elle a un vrai bobaraba" (Es una verdadera mujer africana, tiene unas nalgas voluminosas). La palabra aparece en el álbum Ivoire feeling de DJ Mix y DJ Eloh.

CHOCO significa guapo o bonito, y también elegante. Esta palabra resulta del apócope de chocolate. Suele designar a una persona hermosa o elegante; por ejemplo: "Regarde mon professeur, il choco ce matin" (Mira al profesor, está muy elegante esta mañana). Esta palabra aparece en el álbum Le meteorman del artista Kedjevara.

GATER significa alborotar. Se trata de un caso de resemantización del verbo "gâter" (fr) (estropear). Adquiere un sentido figurado en el contexto de enfrentamiento, en el francés marfileño. Suele emplearse como forma enfática indefinida; por ejemplo, "C'est gâté" para designar una situación revuelta y caótica. Ejemplo: "C'est gâté sur le campus, il y a un affrontement entre la FESCI et la police" (Está todo revuelto en el campus, hay enfrentamientos entre la $\mathrm{FESCI}^{5}$ y la policía). La palabra aparece en el álbum One Vouvou, del artista Force One.

LOLO significa teta o pecho grande. Es una metáfora que se inspira en la papaya (lolo o solo) para referirse a 
pechos abultados; por ejemplo: "Marie a de vrai lolo" (María tiene unas tetas muy grandes). Aparece en el álbum Eternel del artista Meiway.

VALIDER significa aprobar. Se trata de un caso de ampliación semántica del verbo "valider" (fr), validar. Sin embargo, al pasar al francés local, se emplea con el sentido figurado y experimenta a la vez una ampliación semántica; por ejemplo: "Jean a validé son baccalauréat" (Juan aprobó el bachillerato). La palabra aparece en el álbum Remuer la bouteille del artista DJ Kedjevara.

VI significa timador, embaucador. Es una sigla derivada de "Vendeur d'Illusion", que significa literalmente vendedor de ilusiones; por ejemplo: "Arrête de nous vi, on sait tous que ta maman est au village et non en France" (Deja de mentirnos, todos sabemos que tu madre vive en el pueblo y no en Francia). Esta expresión fue acuñada por el artista Josey en su álbum Vendeur d'illusion.

WOLOSSO significa prostituta o fulana. Es un préstamo del dioula al francés marfileño. Se suele utilizar como un sustantivo; por ejemplo: "Cette fille sort chaque soir et rentre chaque matin, dja c'est une wolosso" (Esta chica sale todas las noches y vuelve cada mañana; es una prostituta. Esta palabra aparece en el álbum Ivoir feeling de Dollard DJ.

ZANGO significa vestir bien. Es un préstamo del nouchi; por ejemplo: "Voisine tu es zango comme sa là, où vastu?" (Vecina, estás muy bien vestida, ¿adónde vas? Nótese que el neologismo aparece en el álbum Zango del grupo Force One.

ZANKOUNANA significa mujer materialista. Es un préstamo del fang (lengua camerunesa) al francés marfileño; por ejemplo: "Cette fille là si tu as fait l'erreur de la courtiser elle va te ruiner c'est une vrai zankounana" (Si cometes el error de cortejar a esa chica, estarás jodido porque te arruinará). La palabra aparece en el álbum Zankounana del grupo Fanicko.

Unidades fraseológicas. DERRIERE VILLAGE Y'A VILLAGE significa "No siempre se topa con otra persona más fuerte". Esta expresión significa literalmente: "siempre hay un pueblo detrás de otro". En el imaginario popular, el pueblo representa la fuerza colectiva; por ejemplo: "Aujourd'hui là vous allez comprendre que derrière village y'a village" (Hoy sabréis que hay alguien más fuerte que vosotros). Esta expresión aparece en el álbum Le temps est menacé del grupo Bénédiction.

ROULER MOUTOU significa menear las nalgas. Esta expresión resulta de la combinación de dos componentes heterógamos: "rouler" (mover), del francés, y "mouttou" (nalgas), préstamo del apolo6; por ejemplo: "Lors de la fête Abissa [...] les femmes dansent en roulant leur Mouttou" (Durante la fiesta Abissa [...] las mujeres bailan moviendo las nalgas). Esta expresión fue acuñada por el artista Meiway, quien la publicó en su álbum Professeur M23, del 2012.

Neologismos y unidades fraseológicas del rap. Neologismos del rap. DOUAHOU significa suerte, éxito, fortuna. Es un préstamo del dioula. Suele emplearse por los "brouteurs", cuando consiguen estafar mucho dinero; por ejemplo: "Aujourd'hui Jean, le bouteur a eu douhaou, il a gagné beaucoup d'argent"' (Hoy le ha tocado la 
suerte a Juan, ganó mucho dinero). La palabra aparece en el álbum Cubisme del grupo del artista Kiff No Beat.

GOUMIN (-GOUMIN) significa mal de amores. Es un préstamo del nouchi que se emplea como un sustantivo; por ejemplo: "Après cette fait larguer par son mari goumin-goumin veut la tuer" (Se muere de pena de amores, por haber sido abandonada por su marido). La palabra goumin-goumin aparece en el álbum Follow me go, 2016, del grupo Force One.

MANAOUA significa obrero o jornalero. Se trata de un neologismo nouchi que se emplea como préstamo al francés marfileño; por ejemplo: "On a besoin de deux manaouas pour décharger le conteneur" (Necesitamos dos jornaleros para descargar el contenedor). El término manaoua aparece en el álbum Approchez regardez, 2017, del grupo Kiff No Beat.

MOUSSER significa prosperar o tener éxito. Se trata de un caso de ampliación semántica del verbo "mousser" (fr.), que significa espumar; por ejemplo: "Tu mousses fort en ce moment car toutes tes activités marchent bien" (Tienes éxito estos días, todas tus actividades funcionan muy bien). Esta palabra aparece en el álbum Menbalescouilles de Shado Chris.

Unidades fraseológicas del rap. ENFANT DE BOSS C'EST BOSS significa padre rico, hijo rico. Suele emplearse en el lenguaje juvenil para referirse a hijos de familias adineradas; por ejemplo: "Toi tu dépenses dèh, vraiment enfant de boss c'est boss" (Gastas mucho dinero; de verdad, padre rico, hijo rico). La expresión aparece en el single "Enfant de boss c'est boss" del artista Supect 95.
GATER CEUR significa molestar(se) o irritar(se). Es una expresión neológica del nouchi local, que se emplea en sentido figurado y que significa irritar(se); por ejemplo: "Quand on t'enseigne une leçon et que tu ne comprends pas, sa gâte cœur" (Cuando te enseñan una lección y no entiendes, te irritas). La expresión aparece en el álbum Cubisme del grupo Kiff No Beat.

GERER LE BIZZI significa, prostituirse o venderse. Suele referirse a chicas que mantienen relaciones sexuales solo por dinero; por ejemplo: "Celle-là c'est une gereuse de bizzi je connais trois de ses gourous" (Esta chica se vende; conozco a tres de sus clientes). Esta expresión aparece en el álbum Bizzi, 2017, de Chado Chris.

LA VIE DE LOUGA significa vida lujosa. Se suele aplicar a gente que vive a cuerpo de rey. La expresión se deriva del nombre François Louga, artista marfileño conocido por sus excentricidades vinculadas a la vida lujosa. Ejemplo: "Tu mènes la vie de louga, tu fréquentes uniquement les endroits couteux" (Llevas una vida de lujo, solo frecuentas lugares lujosos). Esta frase aparece en el álbum Cubisme del grupo Kiff No Beat.

\section{La influencia de los géneros musica- les y análisis de resultados}

El impacto sociológico de los fenómenos musicales. Como medio de interacción social, estos géneros musicales se convierten en unas prácticas tan particulares como esenciales en la cultura marfileña. Este proceso se debe a tres factores importantes: 1. el lingüístico, 2. el psicológico y 3 . el sociológico. El primero se fundamenta en 
la identificación de los oyentes con el lenguaje o la retórica empleada. Toma en cuenta el estilo expresivo local, basándose en las metáforas y los recursos en clave humorístico típicos. En relación con el segundo factor, este proceso afecta sensiblemente la vida emotiva de los hablantes. Así, tanto con las letras como con la misma melodía, se difunden mensajes tendentes a conmover, incidiendo en los sentimientos profundos de los oyentes. Esto justifica que reaccionen tan espontáneamente al oír esta música que se puede considerar como parte de su vida anímica. En cuanto al tercer factor, alude a las temáticas atinentes a la experiencia y a los intereses vitales de los locutores. Estos últimos se sienten identificados con estos mensajes, que tratan de describir de forma crítica las prácticas sociales, costumbres, ideologías, etc.

\section{Análisis de resultados. La valoración} cuantitativa. Nuestro glosario cuenta conjuntamente con 35 neologismos y expresiones fraseológicas, que se clasifican entre sustantivos, verbos y otras expresiones fijas mediante las que se recogen la visión de los marfileños y su sabiduría popular. Unas son calcos de las lenguas nativas y otras son neologismos. En total, se registran 20 neologismos y 15 expresiones idiomáticas; de los cuales se deducen 13 unidades neológicas del zouglou (6 palabras y 7 expresiones), junto con 11 unidades (9 términos y 2 expresiones) procedentes del coupé-décalé y las 8 restantes (4 términos y 4 expresiones) del rap.

Aunque el zouglou y el coupé-décalé son comparativamente los géneros más divulgados, es difícil establecer un impacto distintivo en relación con grado de influencia que poseen.
La valoración cualitativa en relación con el impacto sociológico. Es importante destacar que los elementos registrados pertenecen principalmente al lenguaje juvenil. Además, nuestros informantes admitieron contundentemente su influencia, al considerarlos como unos sociolectos que recogen conceptualmente ideas o juicios colectivos acerca de prácticas y experiencias de su vivencia cotidiana.

En referencia al fenómeno de apropiación del nouchi por el francés marfileño, habría que resaltar el predominio de unidades neológicas registradas en el habla de los jóvenes; por ejemplo: "mougou pan" (aprovecharse sexualmente de alguien), "tomber fan" (enamorarse), "être popodipo" (zanjar un asunto en el acto), etc. Además, este proceso lleva necesariamente a plantear la problemática de la configuración sociolingüística de este país.

\section{Conclusión}

Se evidencia la apropiación del nouchi mediante el empleo de los elementos verbales proporcionados, como consecuencia de la influencia de los géneros musicales aludidos en el lenguaje juvenil y en la formación del francés marfileño. Esta realidad coincide con la valoración de los propios hablantes e informantes cuyo juicio fue necesario para llegar a esta aseveración.

Por lo demás, se podría matizar esta valoración, desde la perspectiva crítica, como hechos casuales atinentes a un efecto de moda o como una realidad lingüística significativa, teniendo en cuenta el arraigo de la mayoría de estas unidades expresivas. Sea cual sea la apreciación particular, 
al cerrar estas líneas, hemos de percatarnos de varios fenómenos lingüísticos sumamente interesantes. Asimismo, considerando los cambios léxico-semánticos habría que destacar la automatización del francés marfileño. Hoy, resulta imposible negar el fenómeno de apropiación lingüística del nouchi por el francés local, lo cual termina incidiendo sistemáticamente en la configuración tradicional del paisaje sociolingüístico. Tampoco se puede descartar el impacto de la música zouglou, el coupé-décalé y el rap en esta dinámica lingüística y sociolingüística.

En última instancia, cabe apuntar que el enriquecimiento de las lenguas a través de medios de expresión como la literatura, el periodismo, etc., no es nada nuevo ni ajeno a la investigación lingüística. A lo largo de la historia, novelistas, músicos y otros autores han contribuido a desarrollar el inventario léxico de las lenguas, con neologismos variados, destinados a representar conceptos y vacíos de significación. Por consiguiente, resulta importante advertir que esta exploración lexicológica constituye una orientación científica de interés, en relación con la emergencia y autonomización del francés marfileño, aunque quedan otras fuentes documentales (refiéranse al periódico satírico Gbich), no menos importantes, por explorar a fin de dar cuenta del conjunto de recursos que intervienen en este proceso.

\section{Notas}

1. Neologismo derivado del francés "boucan" (alboroto o ruido). Al emplearse metafóricamente, significa: exhibirse, ostentarse o darse por ver.
2. Se interrogaron a unos 30 informantes de la ciudad de Abiyán. Son 5 mujeres y 25 hombres cuya edad oscila entre los 17 y 40 años. En general, tienen un nivel escolar medio. Se clasifican entre funcionarios, comerciantes, obreros, etc.

3. Brouteurs: es un neologismo derivado de "brouter" (pacer). Significa metafóricamente estafador cibernético o cibercriminal.

4. Bété: es una lengua del grupo Krou, que ocupa el suroeste del territorio marfileño.

5. FESCI: Federación estudiantil de Costa de Marfil, sindicato de alumnos y estudiantes.

6. Lengua del grupo akan, que se habla principalmente en Bassam (ciudad balnearia, a unos $30 \mathrm{~km}$ al suroeste de Abiyán).

7. Timadores cibernéticos.

8. Práctica cibercriminal correspondiente a la estafa en internet.

9. "Gorou", préstamo relexicalizado que designa a una persona con alto poder económico o persona mayor y adinerada que mantiene a una chica. Es equivalente del término inglés: "Sugar Daddy".

\section{Artistas citados}

Bénédiction, "Quand quelqu'un laisse quelqu'un prend", Le temps est menacé, 2018.

DJ Kedjevara, "Remuer la bouteille", Remuer la bouteille, 2016.

DJ mix y DJ Eloh, "Bobaraba", Ivoir feeling, 2005.

Dollard DJ, "Wolosso", Ivoir feeling, 2007.

Fanicko, "Zankounana", Zankounana, 2016.

Force One, "Follow me go", Follow me go, 2016.

Force One, "Vouvou", Vouvou, 2018.

Force One, "Zango", Zango, 2016. 
Josey, "Vendeur d'illusion", Vendeur d'ilusion, 2017.

Kiff No Beat, "Approchez regardez", Cubisme, 2017.

Kiff No Beat, "Douahou", Cubisme, 2015.

Kiff No Beat, "La vie de louga", Cubisme, 2015.

Kiff No Beat, "Sa gate coeur", Cubisme, 2015.

Lunic, "Abidjan est risqué", Abidjan est risqué, 2017.

Magic Système, "Popodipo", Un gaou a París, 2003.

Magic Système, "Tapé dos", Ki di mié, 2007.

Meiway, "Miss lolo", Eternel, 2001.

Meiway, Rouler moutou, Professeur M23, 2012.

Revolution, "Je bois plus", Je bois plus, 2016.

Shado Chris, "Bizzi", Bizzi, 2017.

Shado Chris, "Menbalescouilles", Menbalescouilles, 2017.

Serge Benaud, "Tu étais où", Acelerate, 2016.

Supect 95, "Enfant de boss c'est boss", Enfant de boss c'est boss, 2016.

Zouglou Makers, "C sa ki va tuer", Djamo djamo, 2016.

\section{Bibliografía}

Aboa, A. L. (2008). "La Côte d'Ivoire et la langue française, les facteurs d'une appropriation". LTML, N. ${ }^{\circ} 2008$, p. 1-13. (2012). "Le français dans le contexte urbain de Côte d'Ivoire". Sudlangue, N. ${ }^{\circ} 18$, vol. 2 , pp. 72-83.

Boutin, A. B. (2002). Description de la variation : études transformationnelles des phrases du français de Côte d'Ivoire. Thèse Doctorale, Grenoble 3, p. 404.
(2011). "Peut-on parler d'un français ivoirien de l'élite?" HAL-Francophonie Afrique et Océan Indien, Toulouse CNRS, pp. 49-58.

Cross, I. (2010). "La música en la cultura y la evolución". Epistemus, Universidad de Cambridge, vol. 1, pp. 9-19.

Duponchel, L. (1972). Contribution à l'étude lexical du français de Côte d'Ivoire: problème de néologie et enseignement de vocabulaire. ILA, Université d'Abidjan. (1975). Dictionnaire du français de Côte d'Ivoire. ILA, Université d'Abidjan.

Kouadio N. J. (2003). Le français en Côte d'Ivoire: de l'imposition à l'appropriation décomplexée d'une langue exogène". L'émergence du domaine ou du monde francophone, N. ${ }^{\circ}$ 40/49, pp. 179-197.

Lafage, S. (2002). "Le lexique français de Côte d'Ivoire. Appropriation et créativité". Réseau des observatoires du français contemporain en Afrique, N. ${ }^{\circ} 16-17$, vol. 2, pp. 226-229.

Llamas, J. (2011). "Música y Lenguaje". Sinfonía Virtual, Revista de Música clásica y reflexión musical, 19.

Ngalasso, M. y Ploog, K. (1998). "Le français des écoliers abidjanais. La revanche de la rue sur l'école?". Francophonie africaine, Rouen, CNRS, pp. 67-79.

Tshigfrey, T. (1995). "Procédés morphologiques de néologie dans un corpus de chansons zouglou en français". Persée, N. . 33, pp. 71-78.

Yao, K. (2013). "El nouchi, ¿pidgin, argot o criollo?". Estudios de 
África y Asia, N. ${ }^{\circ} 2$ (151), vol. 48, pp. 537-556.

Yao, K. (2011). "La libertad de expresión y el lenguaje sexual en la música zouglou y coupé-décalé" de Costa de Marfil". Arbor, CSIC, vol. 187-751, pp. 983-992. 
